\title{
The Dynamic Effects of Psychological Contract to College Physical Education Teachers: an Network Organization Perspective
}

\author{
Yuan Xiaozhi ${ }^{1}$, Wan Ping ${ }^{2}$, Zhou Hang ${ }^{2}$ and Li Zhenliang ${ }^{1, *}$ \\ ${ }^{1}$ P.E. Department, Jinggangshan University, Ji'an Jiangxi, China \\ ${ }^{2}$ P.E. Department, Shanghai Finance University, Shanghai, China \\ *lzl80101@163.com
}

\begin{abstract}
With the development of the network organization, the psychological contract theory has become an important tool to promote the efficiency of the network organization. In this paper, we test the psychological contract problems from college physical education teachers, and try to improve their mental health. By using empirical analysis, the result shows that in fourdimensional degree of PE Teachers' psychological contract: RMSEA=0.06, GFI=0.95, $C F I=0.94, I F I=0.94, N N F I=0.9$. And in three-dimensional degree of colleges responsibility: RMSEA $=0.066, G F I=0.92, C F I=0.93, I F I=0.93, N F I=0.92$. So that , the dimensional structure is a reasonable assumption, at the same time, the overall situation of university teachers' psychological contract is good, the degree of importance as follows: development contract, the basic guarantee contracts, contract trading norms, interpersonal contract, balancing contracts, management contracts and innovation contract.
\end{abstract}

Keywords: Psychological contract, Network organization, PE teachers, University responsibility, Four-dimensional structure

\section{Introduction}

Economic globalization and information technology have increased the uncertainty of the external environment of enterprises; enterprises rely on the limited internal resources increasingly difficult to cope with the increasingly fierce competition. Because of the strong adaptability of the network organization, more and more enterprises begin to choose the competition strategy. The research on the efficiency of the network has been regarded as an important part of the research [1]. However, in the past, the efficiency of network organization is studied, and it is from the following two aspects: Based on the analysis of the efficiency of network organization from the perspective of economics, the standard of judging the efficiency of network organization is to achieve cost minimization two. However, based on the perspective of economics and business theory, the analysis of the efficiency of the network organization, there is a natural defect [2-3]. Transaction cost theory is only concerned about the cost of the transaction, but the efficiency of network organization is the improvement of the performance of the nodes, but not the performance of a single node enterprise. Therefore, the transaction cost theory cannot explain the efficiency of network organization. In addition, there is no hierarchy among the nodes of the network organization. It is a strategic cooperative relationship. The nodes have their own economic interests, which make the contract mechanism weaken, and the contract mechanism cannot promote the efficiency of network organization.

* Li Zhenliang is corresponding author. 
The reform of higher education in China has been deepened and ordinary colleges and universities are facing new opportunities and challenges, and the vitality of the University depends on the situation of college teachers. China's economic stability and stability of GDP, the national total output value of second in the world, colleges and universities is to cultivate talent and talent gathering place, but also an important factor affecting China's economy can occupy the commanding heights of the world in twenty-first Century. In order to keep sustainable development and enhance the core competitiveness of colleges and universities, we cannot do without the high efficiency and high quality teachers. The psychological contract was first proposed in 1960s by C. Argyris in his book understanding organizational behavior, which is used to describe the relationship between subordinates and supervisors. The definition of psychological contract is more than the norm [4]. This study is defined as the responsibility of university to physical education teachers and the responsibility of physical education teachers in Colleges and universities, which includes two aspects: University Physical Education Teachers' psychological contract and psychological contract of university responsibility". Psychological contract is more and more modern enterprise, the psychological contract is extended to the research of public management is relatively small, especially the research of College Physical Education Teachers in this special group is almost not involved, therefore, to carry out physical education teachers psychological contract and its related factors can improve the scope and object of psychological contract, and provide important reference for the reform of personnel system in China. [5] To study the contents, structure and influence factors of the psychological contract, it is beneficial to correctly understand and deal with the relationship between University and physical education teachers, reduce the loss of physical education teachers, improve the teachers' loyalty and cohesion. Empirical research from influencing factors of middle school PE teachers' psychological contract, hoping to give the relevant units, experts and leaders to bring help.

\section{Literature Review}

\subsection{Psychological Contract}

In the past, the relationship between psychological contract and organizational performance is discussed, which is based on the two aspects: the positive promotion effect of psychological contract and psychological contract violation to the organizational performance [6]. On the one hand, the internal mechanism and mechanism of psychological contract and organizational performance are discussed from the theoretical level. On the basis of the previous research results of psychological contract, Krstev (2014) introduced the concept of efficiency into the research of psychological contract, and explored the dynamic changes of psychological contract, and the factors that affect the change [7]. Psychological contract is the expectation of both the employees and the organization. When the psychological contract is satisfied, it means that the employee and the organization can meet the expectation. This will improve the staff working attitude and enthusiasm, and then promote the organization performance. This level of psychological contract research is more concerned about how the psychological contract from the perspective of the psychological contract, and through the way of theoretical interpretation of the role of psychological contract and organizational performance. But more scholars explore the relationship between psychological contract and performance by using empirical research. In the research of the relationship between psychological contract and performance by using empirical method, this paper finds out that the psychological contract is a narrow concept, which 
is defined as the perception of both parties' responsibility and obligation. On the other hand, the influence of the employee's working behavior and work results is analyzed from the perspective of psychological contract violation.

Psychological contract violation refers to the strong emotions and emotional experience generated by the individual's perception of the organization in practice and not fully fulfilling the responsibilities of the psychological contract [8]. First of all, the psychological contract violation of the attitude of the staff will have a great impact. It is believed that the original trust and psychological contract violation is negative correlation, once the psychological contract rupture will reduce the individual to the company's trust, the individual thinks that the company does not care about their own interests, reduce the responsibility of the company's obligations. The theory model of psychological contract violation, organizational justice, organizational citizenship behavior of the three, the study found that the violation of psychological contract will lead to the staff of the organization is not fair, so as to produce a variety of emotional reaction. Such psychological contract violation is related to the employee's performance and organizational citizenship behavior, and the relative degree of the psychological contract violation to the organization's citizenship behavior is stronger than the other organization members. Finally, the psychological contract violation has a profound impact on the performance of the staff. Through the above analysis, we can see the relationship between psychological contract and performance in the context of family level. Some scholars believe that the psychological contract can promote the performance; some think that the two are not related.

\subsection{Network Organization}

To define the connotation of network organization is a scientific and reasonable definition, and it is the basis of the research of network organization. The scholars who participated in the research of network organization, such as the collection of the collective resources of the enterprise, have not formed a unified consensus. From the perspective of organization form, the network organization is defined as a kind of institutional arrangement between the division level and the market [9]. From the aim of establishing the network organization, the paper focuses on the purpose of establishing the network organization, which is to obtain the resources technology or the competitive advantage of the organization. From the point of view of network organization's internal process control, the network organization is defined by the scholars, and then the network organization operation mechanism is analyzed.

Network organization is a dynamic combination of active nodes; on the one hand, the node enterprise may enter or exit the network organization at any time. The network protocol is not a strong binding force to the nodes in the system. On the contrary, it is more and more to guide and coordinate for the node enterprises. According to Coase's firm theory from the perspective of transaction cost economics, when the enterprises to obtain technical resources or the network organization cost is higher than the market cost, the node enterprises will automatically leave network organization [10]. When the network organization that the node enterprises can bring more value for the development of the network, it will absorb more nodes enterprise. On the other hand, the node enterprise is dynamic and flexible. The nodes in the network organization can receive and transmit information independently, and they will carry on the processing, the meaning, the analysis, the independent decision-making and take the corresponding countermeasure. Node enterprise will automatically adjust according to the target, operation process and the change of its strategy. 


\section{Research Object and Main Method}

\subsection{Questionnaire Survey}

According to the famous Chinese sports colleges and universities of Zhejiang geographical advantages of the distribution, take out 13 universities, as Beijing Sport University, Tongji University, Wuhan Sports Institute, Guangzhou Sports University, Jinggangshan University, the basic characteristics of the information was shown in Table 1.

Table 1. Basic Characteristics of Questionnaire Survey $(n=13 ; n=55)$

\begin{tabular}{|c|c|c|c|c|c|}
\hline Index & Classification & interview & Pro.(\%) & Survey & Pro. $(\%)$ \\
\hline \multirow{2}{*}{ Gender } & Male & 9 & 69.23 & 34 & 61.82 \\
\hline & Female & 4 & 30.77 & 21 & 38.18 \\
\hline \multirow{4}{*}{ Age } & Under 35 & 3 & 23.08 & 15 & 27.27 \\
\hline & 36-45year & 5 & 38.46 & 16 & 29.10 \\
\hline & $46-55$ year & 3 & 23.08 & 18 & 32.73 \\
\hline & More than 56 & 2 & 15.38 & 6 & 10.90 \\
\hline \multirow{3}{*}{ Education } & Graduate & 10 & 76.92 & 30 & 54.55 \\
\hline & Undergraduate & 3 & 23.08 & 19 & 34.55 \\
\hline & Specialist & 0 & 0.00 & 6 & 10.90 \\
\hline \multirow{3}{*}{ Title } & Professor & 5 & 38.46 & 10 & 18.18 \\
\hline & Associate Professor & 6 & 46.16 & 29 & 52.73 \\
\hline & Other & 2 & 15.38 & 16 & 29.09 \\
\hline \multirow{10}{*}{ School } & Beijing Sport Uni. & 3 & 23.09 & 9 & 16.36 \\
\hline & Tongji Uni. & 2 & 15.39 & 8 & 14.55 \\
\hline & Wuhan Sports Inst. & 1 & 7.69 & 7 & 12.74 \\
\hline & Guangzhou Sports Uni. & 1 & 7.69 & 6 & 10.91 \\
\hline & Jinggangshan Uni. & 1 & 7.69 & 6 & 10.91 \\
\hline & $\begin{array}{l}\text { Shanghai Institute of Physical } \\
\text { Education }\end{array}$ & 1 & 7.69 & 5 & 9.09 \\
\hline & Tsinghua Uni. & 1 & 7.69 & 4 & 7.27 \\
\hline & Xi'an Physical Education Uni. & 1 & 7.69 & 4 & 7.27 \\
\hline & Nanchang Uni. & 1 & 7.69 & 3 & 5.45 \\
\hline & Hainan Uni. & 1 & 7.69 & 3 & 5.45 \\
\hline
\end{tabular}

\subsection{Research Method}

The main research method including:

1) Literature Method: In CNKI, Tongji University and University of Jinggangshan library access to domestic and foreign related research literature, literature reviews at home and abroad of psychological contract results, summarized the related theories of psychological contract of advance and progress, especially by foreign scholars use the theory and method, on the basis of existing research results and research methods of the proposed the theoretical framework and hypotheses, and the investigate measure of empirical research in the concept of the table data in the search for a useful reference. 
2) Interview Method: Interview is the expert of the psychological contract of the forum and telephone interview. And for the psychological contract of the idea of the adjustment, consolidation and expansion, learn from their valuable experience, for the content of the article, the validity of the questionnaire to lay a good solid foundation.

3) Questionnaire Survey: Questionnaire survey is an important research method of the article, through the study of the structure of the empirical study of the measurement of the variables, and in the empirical study through the larger scale of the questionnaire to verify the idea, for the construction and results of the article provide protection. The article uses five levels of evaluation, scoring for the 1-5 points, the impact is very big for 5 points, the impact is greater for 4 points, the impact is generally 3 points, the impact is smaller for 2 points, the impact is very small for 1 points, 1-1.50 is very small, 1.51-2.50 for the impact of the general, 3.51-4.50 for the impact is larger, 4.51-5 is very big; the higher the score, the greater the impact. The expert questionnaire issued 13 copies, 13 copies, 13 effective, $100 \%$, effective rate 100 , the university sports teachers' questionnaire issued 70, 60 copies, 55 valid questionnaires, the recovery rate is $85.71 \%$, the effective rate is $91.67 \%$.

4) Statistical Method: According to the needs of the research, this study mainly uses the statistical analysis tool of social science statistical software package SPSS16.0, EXCELL and LISREL8.51 three kinds of software, mainly including: analysis of variance, validation and exploratory factor analysis, factor analysis, etc.

5) Logical Reasoning: By using the method of comparison, deduction, induction, analysis and reasoning, the results of the statistical significance of the data were analyzed and summarized.

\section{Empirical Analysis}

\subsection{Data Collection}

Research on 13 psychological contract of the experts, mainly to carry out the following: first of all, the psychological contract of the former scholars summarized and summed up; second is to conduct semi-structured interviews, the interview results record, summary, sorting and overall results, according to the interview results and combined with the actual characteristics of the study, the final analysis and ranking of the interview, the psychological contract and the contribution rate of college sports teachers, which is based on the frequency and contribution rate as 16 indexes, the content of the content of the university responsibility as 12 indexes.

\subsection{Data Analysis of Psychological Contract Factors}

4.2.1. Psychological Contract of the Physical Education Teachers' Responsibility: 10 colleges and universities to grant formal questionnaire measuring 55 parts, with SPSS16.0 measurement factor questionnaire results are exploratory factor analysis, principal component extracted common factor method, taking eigenvalues greater than 1 to intercept the common factor standard. In the sports teacher responsibility 16 related projects, Table 21 results show: the total variance of four common factors to explain the cumulative $70.720 \%$, which the first common factor holds 30.166 percent, the second common factor holds $17.634 \%$, 3 common 
factor occupies $13.433 \%$ and fourth common factor occupies $9.487 \%$. Scale KMO is 0.863 , indicating that suitable for exploratory factor analysis; the same time, Barlett test of sphericity value of 2621.633, $\mathrm{df}=220, \mathrm{P}=0.000$, there was a significant difference in scale project data between the scale represents not independent, take value is greater relationship, indicating very suitable for exploratory factor analysis. To facilitate the study, Table 22 results show: 1 common factor named PE teachers responsibility transaction specification contract, including sport proficiency, knowledge broad point, good response strategies, high-quality, high-style, Active extracurricular learning and practical teaching ability; the common factor 2 was named the responsibility of PE teachers' interpersonal contract, including the colleague to provide guidance, co-teaching ability, handle the relationship between colleagues, process leading Relations and psychological resilience; the common factor 3 named PE teachers responsible development of innovative contract, including Physical research level, scientific rigor , having more Subject Ability and focus on empirical research, academic correct; the common factor 4 named PE teachers responsible management contract, including teacher competency levels and sports management. Visible, constitute PE teachers responsibility psychological contract has four dimensions, and with the results of the questionnaire pre-test two entirely consistent.

Table 2. Total Variance Explained $(n=55)$

\begin{tabular}{|c|c|c|c|c|c|c|}
\hline \multirow{2}{*}{ Component } & \multicolumn{3}{|c|}{ Initial Eigenvalues } & \multicolumn{3}{c|}{ Extraction Sums of Squared Loadings } \\
\cline { 2 - 7 } & Total & $\begin{array}{c}\% \text { of } \\
\text { Variance }\end{array}$ & $\begin{array}{c}\text { Cumulative } \\
\%\end{array}$ & Total & $\begin{array}{c}\% \text { of } \\
\text { Variance }\end{array}$ & $\begin{array}{c}\text { Cumulative } \\
\%\end{array}$ \\
\hline 1 & 4.827 & 30.166 & 30.166 & 4.827 & 30.166 & 30.166 \\
\hline 2 & 2.821 & 17.634 & 47.800 & 2.821 & 17.634 & 47.800 \\
\hline 3 & 2.149 & 13.433 & 61.233 & 2.149 & 13.433 & 61.233 \\
\hline 4 & 1.518 & 9.487 & 70.720 & 1.518 & 9.487 & 70.720 \\
\hline
\end{tabular}

Table 3. Rotated Component Matrix of PE Teachers' Responsibility $(n=55)$

\begin{tabular}{|c|c|c|c|c|}
\hline \multirow{2}{*}{ Index } & \multicolumn{4}{|c|}{ Component } \\
\cline { 2 - 5 } & 1 & 2 & 3 & 4 \\
\hline Sports proficiency & .943 & & & \\
\hline Good strain strategy & .690 & & & \\
\hline High quality and style & .887 & & & \\
\hline Active extracurricular learning & 783 & & & \\
\hline Practical teaching ability & .815 & & & \\
\hline Provide guidance to colleagues & & .853 & & \\
\hline Cooperative teaching ability & & .661 & & \\
\hline relationship between colleagues & & .776 & & \\
\hline Deal with leadership & & .642 & & \\
\hline Psychological adaptive ability & & .78 & & \\
\hline Sports scientific research level & & & .569 & \\
\hline Rigorous scientific research & & & .804 & \\
\hline Multi discipline ability & & & .861 & \\
\hline Empirical research & & & .813 & \\
\hline Class teacher ability & & & & .789 \\
\hline Sports management level & & & & .879 \\
\hline
\end{tabular}


4.2.2. The Four Dimension Structure of Psychological Contract: In order to verify the responsibility of PE Teachers' Psychological Factors contract four dimensional structure reasonable hypothesis proposed exception to compare three competing models demonstrate, respectively, 3 dimensions, two dimensions and one dimension, three dimensions include transaction contract, interpersonal contract and the development of innovative contract; 2 dimensions include transaction contract and the development of innovative contract; 1 dimension to merge all four factors. In the dimension structure inspection, meaning the use of project confirmatory factor analysis is that you can better compare the advantages and disadvantages of multiple dimensions between models to determine the best model, the best indicators to measure the model structure more, $\mathrm{X}^{2} / \mathrm{df}$, RMSEA, GFI, CFI, IFI, NNFI are some of the most important indicators, $\mathrm{X}^{2} / \mathrm{df}<3$ shows the structure of the model structure is very good, when the sample reaches a certain amount, $\mathrm{X}^{2} / \mathrm{df}<5$ can accept, $\mathrm{X}^{2} / \mathrm{df}>5$ to generally do not accept, RMSEA values closer to 0 the better, 0.08 or less justify the model structure, GFI, CFI, IFI, NNFI closer to 1 , the better, greater than 0.90 are considered reasonable structure. The results in Table 4 was: four-dimensional structures "of PE Teachers responsibility" psychological contract samples to achieve the best results, the four dimensions $\mathrm{X}^{2} / \mathrm{df}=377.412 / 84=4.493<5, \mathrm{RMSEA}=0.06<0.08, \mathrm{GFI}=0.95, \mathrm{CFI}=0.94, \mathrm{IFI}=0.94$, $\mathrm{NNFI}=0.93$ is greater than 0.90 .It is obvious that the four dimension model fits the ideal, and the four dimension model is obviously superior to the other 3 dimensions model, and it is reasonable to explain the hypothesis that the four dimensional structure of the University PE teacher is reasonable.

Table 4. Confirmatory Factor Analysis of Teacher's Responsibility $(n=55)$

\begin{tabular}{|c|c|c|c|c|c|c|c|c|c|c|}
\hline Model & $\mathrm{X}^{2}$ & $\mathrm{df}$ & $\mathrm{X}^{2} / \mathrm{df}$ & GFI & RMSEA & RMR & NFI & NNFI & CFI & IFI \\
\hline Four dim. & 377.41 & 84 & 4.493 & 0.95 & 0.06 & 0.051 & 0.94 & 0.93 & 0.94 & 0.94 \\
\hline Three dim. & 458.52 & 86 & 5.332 & 0.83 & 0.12 & 0.083 & 0.81 & 0.82 & 0.77 & 0.77 \\
\hline Two dim. & 538.38 & 88 & 6.118 & 0.78 & 0.15 & 0.091 & 0.77 & 0.75 & 0.72 & 0.72 \\
\hline One dim. & 641.88 & 92 & 6.977 & 0.71 & 0.21 & 0.095 & 0.69 & 0.67 & 0.70 & 0.70 \\
\hline
\end{tabular}

\subsection{The Psychological Contract of University Responsibility}

4.3.1. Psychological Contract of University Responsibility: A total of 55 questionnaires were issued to 10 universities. The results were analyzed by SPSS16.0. The factors were extracted by principal component method, and the standard of the factor was greater than 1 . In the "university responsibility" 12 related items, table 5 shows that the total variance explained by 3 factors is $67.918 \%$, of which $33.777 \%$ (first, second, third, $15.521 \%$ ). The value of KMO was 0.821 , indicating that it was suitable for exploratory factor analysis. At the same time, the Barlett test value was 3061.869 , $\mathrm{df}=456, \mathrm{P}=0.000$, and the data were very significant. For the convenience of study, table 6 shows: 1 public factors named "the responsibility of university basic guarantee contract", including "pay for performance" reasonable ", title," fair "evaluation of justice" and "welfare rationalization" 4 indicators; factor 2 named the responsibility "the development of contract", including "learning exchanges", "internal rotation", "rational research award" and "school learning exchange" 4 indicators; factor 3 was named the responsibility "balance contract", including "physical education" diversification ", provide challenging work", "the sports teaching workload of basic balance" and "protection of sports teaching safety" 4 indicators, and questionnaire pretest two results. 
Table 5. Total Variance Explained $(n=55)$

\begin{tabular}{|c|c|c|c|c|c|c|}
\hline \multirow{2}{*}{ Component } & \multicolumn{3}{|c|}{ Initial Eigenvalues } & \multicolumn{3}{c|}{ Extraction Sums of Squared Loadings } \\
\cline { 2 - 7 } & Total & $\begin{array}{c}\text { \% of } \\
\text { Variance }\end{array}$ & Cumulative \% & Total & $\begin{array}{c}\text { \% of } \\
\text { Variance }\end{array}$ & Cumulative \% \\
\hline 1 & 4.053 & 33.777 & 33.777 & 4.053 & 33.777 & 33.777 \\
\hline 2 & 2.234 & 18.619 & 52.396 & 2.234 & 18.619 & 52.396 \\
\hline 3 & 1.863 & 15.521 & 67.918 & 1.863 & 15.521 & 67.918 \\
\hline
\end{tabular}

Table 6. Rotated Component Matrix of University Responsibility ( $n=55)$

\begin{tabular}{|c|c|c|c|}
\hline & \multicolumn{3}{|c|}{ Component } \\
\cline { 2 - 4 } & 1 & 2 & 3 \\
\hline Performance pay is reasonable & .883 & & \\
\hline Title Evaluation Fair & .667 & & \\
\hline Assessment of Justice & .707 & & \\
\hline Rationalization of welfare benefits & .608 & & \\
\hline campus learning exchange & & .890 & \\
\hline Provide internal rotation & & .811 & \\
\hline Reasonable scientific research reward & & -.630 & \\
\hline School internal exchange & & .636 & .884 \\
\hline Sports diversification & & & .885 \\
\hline Challenging work & & & .907 \\
\hline Basic balance of Physical Education & & & .804 \\
\hline Safety of Physical Education & & & \\
\hline
\end{tabular}

4.3.2. The Three Dimensional Structure of Psychological Contract: In order to verify the three dimensional structure of psychological contract of university responsibility, 2 dimensions and 1 dimension are proposed, which are 2 dimensions and 2 dimensions. The 1 dimension is combined with four factors. Table four results show that: the 7 dimension of the psychological contract of "physical education teachers" psychological contract reaches a good sample, the $\mathrm{X}^{2} / \mathrm{df}=305.778 / 66=4.633<5, \quad \mathrm{GFI}=0.92, \quad \mathrm{RMSEA}=0.066<0.08, \quad \mathrm{IFI}=0.93$, $\mathrm{CFI}=0.93$, NNFI $=0.92$ are more than 0.90 in $3 \mathrm{D}, \mathrm{X}^{2} / \mathrm{df}=378.284 / 68=5.563>5,=0.11>0.08$, $\mathrm{GFI}=0.80, \quad \mathrm{IFI}=0.78$, in RMSEA, $\mathrm{CFI}=0.78, \quad \mathrm{NNFI}=0.80, \quad \mathrm{X}^{2} / \mathrm{df}=481.764 / 76=6.339>5$, RMSEA $=0.18>0.08, \mathrm{GFI}=0.75, \mathrm{CFI}=0.73, \mathrm{IFI}=0.73, \mathrm{NNFI}=0.74$, are less than 0.90 . It can be seen that the 3D model fitting is better than the other 2 dimensional models. The 3D model is obviously superior to the other 2 dimensions, which is reasonable.

Table 7. Confirmatory Factor Analysis of University Responsibility $(n=55)$

\begin{tabular}{|c|c|c|c|c|c|c|c|c|c|c|}
\hline Model & $\mathrm{X} 2$ & $\mathrm{df}$ & $\mathrm{X} 2 / \mathrm{df}$ & GFI & RMSEA & RMR & NFI & NNFI & CFI & IFI \\
\hline Three & 305.778 & 66 & 4.633 & 0.92 & 0.066 & 0.052 & 0.93 & 0.92 & 0.93 & 0.93 \\
\hline Two & 378.284 & 68 & 5.563 & 0.80 & 0.11 & 0.086 & 0.80 & 0.80 & 0.78 & 0.78 \\
\hline One & 481.764 & 76 & 6.339 & 0.75 & 0.18 & 0.096 & 0.75 & 0.74 & 0.73 & 0.73 \\
\hline
\end{tabular}




\subsection{Overall Analysis}

College PE teachers of 80 sports teachers' psychological contract questionnaire conducted with SPSS16.0 single sample T-test, Table 8 results show that: in college sports teacher responsibility contract, the transaction contract specifications mean 3.72, standard deviation of 0.89 , and the group $(\mathrm{T}=121.36, \mathrm{P}=0.000<0.01)$, interpersonal contract mean 3.63, standard deviation was 0.83 , and the group $(\mathrm{T}=133.26, \mathrm{P}=0.000<0.01)$, innovation contracts mean 2.53, standard deviation was 0.96 , and the group $(\mathrm{T}=89.32, \mathrm{P}=0.000<0.01)$, management contract with mean 3.03, standard deviation of 0.81 , and the group $(\mathrm{T}=91.33, \mathrm{P}$ $=0.000<0.01)$; the liability contract colleges and universities, The basic guarantee contracts mean 3.92, standard deviation of 0.91 , and the group $(\mathrm{T}=106.63, \mathrm{P}=0.000<0.01)$, development contracts mean 3.92, standard deviation was 0.90 , and the group $(\mathrm{T}=117.28, \mathrm{P}$ $=0.000<0.01$ ), the average balance of the contract is 3.53 , the standard deviation is 0.91 , and the group within $(\mathrm{T}=119.28, \mathrm{P}=0.000<0.01)$; the mean rank order: interpersonal contract, transaction standardized contracts, balanced contracts, development contracts, basic protection contracts, management contracts, innovative contracts. First $T$ values are larger and $\mathrm{P}=0.000<0.01$, explain the psychological contract of PE Teachers difference is very large, it is worth pondering the leaders; secondly sport psychological contract teachers did not reach an average of 4 good level, in addition to the average level of innovation contract poor, others are general level; visible, only the overall situation in general, not with optimism, interpersonal contract the highest responsibility to college contract, the minimum contract is an innovative college sports teacher responsibility, too much contrast between the two, indicating that the school needs Sports teacher development, and the development of PE teachers actually very optimistic indeed, worthy of attention the leaders and departments.

Table 8. Overall Analysis of the Psychological Contract for PE Teachers $(n=55)$

\begin{tabular}{|c|c|c|c|c|c|c|c|}
\hline \multicolumn{2}{|r|}{ Index } & $\mathrm{N}$ & Mean & $\begin{array}{l}\text { Stan. } \\
\text { Dey }\end{array}$ & Ranki & $\begin{array}{c}\mathrm{T} \\
\text { value }\end{array}$ & $\begin{array}{c}\mathrm{P} \\
\text { value }\end{array}$ \\
\hline \multirow{4}{*}{$\begin{array}{l}\text { PE Teachers' } \\
\text { responsibility } \\
\text { contract }\end{array}$} & Transaction specification & 55 & 3.72 & 0.89 & 2 & 121.3 & 0.000 \\
\hline & Interpersonal contract & 55 & 3.63 & 0.83 & 1 & 133.2 & 0.000 \\
\hline & Innovation contract & 55 & 2.53 & 0.96 & 7 & 89.3 & 0.000 \\
\hline & Management contract & 55 & 3.03 & 0.81 & 6 & 91.3 & 0.000 \\
\hline \multirow{3}{*}{$\begin{array}{l}\text { University } \\
\text { contract } \\
\text { responsibility }\end{array}$} & Basic guarantee contract & 55 & 3.92 & 0.91 & 5 & 106.6 & 0.000 \\
\hline & Development contract & 55 & 3.93 & 0.90 & 4 & 117.2 & 0.000 \\
\hline & Balance contract & 55 & 3.53 & 0.91 & 3 & 119.2 & 0.000 \\
\hline
\end{tabular}

\section{Conclusion}

With the presence of continuous distillation Universities complex psychological contract reform, college sports teacher issues, together with colleagues of how to improve their mental health. Analysis and study of 13 experts and 55 sports teachers as experimental subjects, the use of literature, interviews, questionnaires, mathematical statistics and logical reasoning indicator data for their scores by psychological contract. The results show that the teachers college sports psychological contract responsibility four dimensions X2 / df $=377.412 / 84=4.493<5$, RMSEA $=0.06<0.08$, GFI $=0.95$, $\mathrm{CFI}=0.94, \mathrm{IFI}=0.94, \mathrm{NNFI}=0.93$ is greater than 0.90 ; Responsibility of Universities psychological contract in three dimensions X2 / df $=305.778 / 66=4.633<5$, RMSEA $=0.066<0.08, \mathrm{GFI}=0.92, \mathrm{CFI}=0.93, \mathrm{IFI}=0.93, \mathrm{NNFI}=0.92$ is greater than 0.90 ; main conclusions are: the responsibility of teachers college sports Psychological any 
contract with four-dimensional structure is a reasonable assumption; psychological contract responsibility of colleges and universities have a three-dimensional structure is a reasonable assumption. The overall situation of University Teachers' Psychological Contract sports in general, the degree of importance as follows: development contract, the basic guarantee contracts, contract trading norms, interpersonal contract, balancing contracts, management contracts and contract innovation.

Psychological Contract of PE Teachers College PE Teachers liability including liability and universities, college teachers to any contract liability psychological Sports Trade standardized contract, interpersonal contract, contract and management contract innovative, four-dimensional structures assume responsibility for University Teachers sport psychological contract is reasonable; psychological contract colleges and universities have a basic responsibility to protect contracts, contract development, contract balance, three-dimensional structure of the Assumption of liability psychological contract is reasonable. The overall situation of University Teachers' Psychological Contract sports in general, the degree of importance as follows: development contract, the basic guarantee contracts, contract trading norms, interpersonal contract, balancing contracts, management contracts and contract innovation.

\section{References}

[1] C. Zhang and X. Chen, "Use of Multimedia in Gross Infective Pathogen Experimental Teaching", Procedia Engineering, vol. 37, (2012), pp. 64-67.

[2] W. Dai and L. Fan, "Discussion about the Pros and Cons and Recommendations for Multimedia Teaching in Local Vocational Schools", Physics Procedia, vol. 33, (2012), pp. 1144-1148.

[3] M. Sigala, "Investigating the role and impact of geovisualisation and geocollaborative portals on collaborative e-learning in tourism education", Journal of Hospitality, Leisure, Sport \& Tourism Education, vol. 11, (2012), pp. 50-66.

[4] A. K. Kim and J. Davies, "A teacher's perspective on student centred learning: Towards the development of best practice in an undergraduate tourism course", Journal of Hospitality, Leisure, Sport \& Tourism Education, vol. 25, (2014), pp. 6-14.

[5] S. Jian-hua and L. hong, "Explore the Effective Use of Multimedia Technology in College Physics Teaching”, Energy Procedia, vol. 17, (2012), pp. 1897-1900.

[6] M. Hu and S. Xu, "Research of Multimedia Teaching on Principles of Management", IERI Procedia, vol. 2, (2012), pp. 666-670.

[7] C. Krstev and A. Trtovac, "Teaching Multimedia Documents to LIS Students", The Journal of Academic Librarianship, vol. 40, no. 2, (2014), pp. 152-162.

[8] Y. Huang and S. Backman, "Experiencing student learning and tourism training in a 3D virtual world: An exploratory study", Journal of Hospitality, Leisure, Sport \& Tourism Education, vol. 13, (2013), pp. 190-201.

[9] C. Wei and Y. Tao, "Application of Multimedia-Aided Project-Teaching Mode in Cultural Education", IERI Procedia, vol. 2, (2012), pp. 538-542.

[10] H. Janta and P. Lugosi, "Migrant networks, language learning and tourism employment", Tourism Management, vol. 33, no. 2, (2012), pp. 431-439. 